\author{
Marquette University \\ e-Publications@Marquette
}

School of Dentistry Faculty Research and

Publications

Dentistry, School of

2010

\title{
Effect of Photobiomodulation on Vinblastine-Poisoned Murine HERS Cells
}

Brian D. Hodgson

Marquette University, brian.hodgson@marquette.edu

B. Pyszka

Michele M. Henry

Medical College of Wisconsin

E. Buchmann

Medical College of Wisconsin

Harry T. Whelan

Follow this and additional works at: https://epublications.marquette.edu/dentistry_fac

Part of the Dentistry Commons

\section{Recommended Citation}

Hodgson, Brian D.; Pyszka, B.; Henry, Michele M.; Buchmann, E.; and Whelan, Harry T., "Effect of Photobiomodulation on Vinblastine-Poisoned Murine HERS Cells" (2010). School of Dentistry Faculty Research and Publications. 21.

https://epublications.marquette.edu/dentistry_fac/21 


\title{
Effect of Photobiomodulation on Vinblastine-Poisoned Murine HERS Cells
}

\author{
B.D. Hodgson, D.D.S., ${ }^{1,2}$ B. Pyszka, D.D.S., ${ }^{2}$ M.M. Henry, ${ }^{3,4}$ E. Buchmann, B.S., ${ }^{3}$ and H.T. Whelan, M.D., ${ }^{2,3}$
}

\begin{abstract}
Objective: The aim of this study was to investigate the effect of near-infrared (NIR) photobiomodulation on the proliferation and glutathione levels in murine Hertwig's epithelial root sheath (HERS) cells after poisoning with vinblastine. Background: Photobiomodulation has been shown to improve wound healing in a number of animal models. There have been no studies on the effect of photobiomodulation on cancer-related chemotherapy injury to the cells that initiate tooth root growth. Materials and Methods: Control groups consisted of murine HERS cells without vinblastine (VB-) and cells with vinblastine at 10, 20, and $30 \mathrm{ng} / \mathrm{mL}$ (VB10, VB20, and VB30). Experimental groups consisted of these same groups with light therapy (VB-L, VB10L, VB20L, and VB30L). The cells were exposed to vinblastine for $1 \mathrm{~h}$. Photobiomodulation consisted of a $75-\mathrm{cm}^{2}$ gallium-aluminum-arsenide light-emitting diode (LED) array at an energy density of $12.8 \mathrm{~J} / \mathrm{cm}^{2}$, delivered with $50 \mathrm{~mW} / \mathrm{cm}^{2}$ power over 256 s. Results: Vinblastine alone significantly decreased HERS cell proliferation and glutathione levels at all concentrations (VB10 $\left[-55 \%, p<1.0 \times 10^{-8}\right]$; VB20 $\left[-72 \%, p<1.0 \times 10^{-9}\right]$; VB30 $\left[-80 \%, p<1.0 \times 10^{-10}\right]$; and VB10 $[-36 \%, p<0.0001]$; VB20 [ $\left.-49 \%, p<1.0 \times 10^{-6}\right]$; VB30 $\left[-53 \%, p<1.0 \times 10^{-7}\right]$ respectively). Photobiomodulation significantly increased cell proliferation at all levels of vinblastine exposure (VB10L $[+50 \%, p<0.0001]$; VB20L [ $+45 \%, p<0.05]$; VB30 [ $+39 \%, p<0.05])$ but not of the control $(+22 \%, p=0.063)$. The photobiomodulation significantly increased glutathione production in all concentrations of vinblastine except $20 \mathrm{ng} / \mathrm{mL}$ (VB10L [+39\%, $p=0.007]$; VB20L [ $+19 \%, p=0.087]$; VB30 [+14\%, $p=0.025])$ and the control $(+12 \%, p=0.13)$. Conclusions: Photobiomodulation demonstrated an improvement in proliferation and glutathione levels in vinblastine-poisoned murine HERS cells.
\end{abstract}

\section{Introduction}

T HE LONG-TERM EFFECTS OF ANTI-NEOPLASTIC THERAPY have gained importance as survival rates from childhood cancers have increased in the past decades. The chemotherapeutic agents used in the treatment of childhood cancers are toxic to proliferating cancer cells through varying mechanisms of action, and all potentially result in injury to nontarget tissues also proliferating at the time of treatment. Acute oral effects include oral mucositis, while long-term effects include decreased salivary gland function and a wide range of dental developmental anomalies, including enamel hypoplasia, microdontia, taurodontia, root blunting and thinning, and hypodontia. ${ }^{1-3}$ The frequency and severity of dental developmental anomalies depend on the developmental stage of the tooth at the time of treatment, as well as the dose and repetition of the chemotherapeutic agent. ${ }^{1}$ Numerous studies of the long-term effects of chemotherapy on dental development have found that the most common abnormality is atypical root morphology. ${ }^{2-7}$

Hertwig's epithelial root sheath (HERS) cells are considered to be the cells responsible for root formation. The apical migration of these cells during root development determines the eventual morphology of the root. ${ }^{8,9}$ HERS cells proliferating at the time of chemotherapy are damaged by the non-selective nature of the drugs, resulting in altered root morphology. ${ }^{10}$ The long-term clinical implications of the short, thin, tapered roots of permanent teeth often seen in childhood cancer survivors include limitations on future orthodontic treatment, prosthetic abutment consideration, and periodontal health. There is currently no treatment or prevention for these morphologic alterations.

Vinblastine is a vinka alkyloid chemotherapeutic agent commonly used in the treatment of childhood cancers, which

\footnotetext{
${ }^{1}$ Marquette University, Milwaukee, Wisconsin.

${ }^{2}$ Children's Hospital of Wisconsin, Milwaukee, Wisconsin.

${ }^{3}$ Medical College of Wisconsin, Milwaukee, Wisconsin.

${ }^{4}$ Marshfield Clinic Research Foundation, Marshfield, Wisconsin.
} 
shows a strong correlation with disturbances in root development. ${ }^{1}$ Vinblastine's primary mechanism of action is the inhibition of microtubule formation, preventing cell proliferation. In addition, vinblastine has been shown to decrease the production of glutathione, an antioxidant that protects cells from free radicals and participates in protein synthesis, resulting in decreased cell viability. ${ }^{11,12}$

Photobiomodulation is a novel, non-invasive treatment that has been shown to help certain cells and tissues recover from injury. ${ }^{13,14}$ The treatment entails irradiating cells or tissues with a specific energy density of light at certain wavelengths in the far-red to near-infrared (NIR) spectrum (630-1000 nm) using low-energy lasers or light-emitting diodes (LEDs).

The purpose of this study was to determine the in vitro effects of photobiomodulation on an immortalized line of murine HERS cells poisoned by the chemotherapeutic agent vinblastine. Vinblastine was chosen as the test chemotherapeutic agent due to its known cause of root morphology alterations, its relative safety when handled, and its direct action on cells without prior metabolic alteration into an active form. We hypothesize that photobiomodulation applied to HERS cells subjected to chemical injury by vinblastine will improve proliferation and function of these cells. Demonstrating this effect may suggest a possible preventive therapy to the developmental root anomalies often seen in the survivors of childhood cancer.

\section{Materials and Methods}

\section{HERS Cultures}

Immortalized murine HERS cells (obtained from Dr. Zeichner-David, University of Southern California) were cultured according to the protocol described by ZeichnerDavid. ${ }^{8}$ Cells were cultured in a $75-\mathrm{cm}^{2}$ tissue culture flask (BD Falcon, Bedford, MA) with Dulbecco's Modified Eagle's Medium, supplemented with $1 \%$ penicillin/streptomycin, $1 \%$ L-glutamine and $10 \%$ heat-inactivated fetal bovine serum, and incubated at $33^{\circ} \mathrm{C}, 5 \% \mathrm{CO}_{2}$. Cells in log phase growth were harvested and cultured in 24-well tissue culture plates and black-walled 96-well tissue culture plates (Corning, Inc., Corning, NY) at a cell density of 62,500 cells $/ \mathrm{cm}^{2}$, as determined by pilot seeding density assays. Cells were then incubated overnight at $33^{\circ} \mathrm{C}, 5 \% \mathrm{CO}_{2}$.

\section{Group assignments}

Plated HERS cell cultures were divided into eight groups based on dose of vinblastine (Abraxis Pharmaceutical Products, Schaumburg, IL) and exposure to light treatment. Control groups consisted of HERS cells without vinblastine $(\mathrm{VB}-)$ and cells treated with 10,20 , and $30 \mathrm{ng} / \mathrm{mL}$ (VB10, VB20, VB30) of vinblastine. Treatment groups consisted of the same groups as the controls, but with photobiomodulation (VB-L, VB10L, VB20L, and VB30L). The test concentrations of vinblastine were based upon an estimated clinical dose. A vinblastine concentration of approximately $7.5 \mathrm{ng} / \mathrm{mL}$ was determined by calculating the estimated cellular concentration of this chemical based on a $20-\mathrm{kg}$ child and a dose of $6 \mathrm{mg} / \mathrm{m}^{2}$. Experiments were conducted on four generations of cells, in triplicates for each group.

\section{Vinblastine exposure}

Twenty-four hours after plating, cultures were exposed to vinblastine diluted in sterile phosphate buffered saline (PBS) for $1 \mathrm{~h}$ at concentrations of $0,10,20$, or $30 \mathrm{ng} / \mathrm{mL}$ added to the culture medium based on group assignments. LD $_{50}$ of vinblastine was determined by pilot dose response assays.

\section{NIR-LED light treatment}

One hour after vinblastine exposure, light treatment groups were exposed to $670 \mathrm{~nm}$ wavelength light generated by gallium-aluminum-arsenide LEDs (Quantum Devices, Inc., Barneveld, WI), at an energy density of $12.8 \mathrm{~J} / \mathrm{cm}^{2}$, delivered with $50 \mathrm{~mW} / \mathrm{cm}^{2}$ power over $256 \mathrm{~s}$, as determined by pilot dose response assays. Control cultures received no light treatment. Cells were incubated for $24 \mathrm{~h}$ at $33^{\circ} \mathrm{C}, 5 \% \mathrm{CO}_{2}$.

\section{Cell proliferation quantification, and glutathione assay}

Forty-eight hours after plating ( $24 \mathrm{~h}$ after vinblastine and photobiomodulation), cell counts were performed under a microscope using a hemocytometer, and glutathione production was measured fluorometrically, as relative fluorescence units (RFU), with a Bio-Tek FLx800 Fluorometer (Bio-Tek Instruments, Inc., Winooski, VT) using the Promega GSH-Glo Glutathione Assay (Promega Corporation, Madison, WI).

\section{Statistical analysis}

All values for cell proliferation (cell counts) and glutathione levels were calculated using Microsoft Office Excel and expressed as mean \pm standard deviation $( \pm S D)$. Comparisons between vinblastine levels and light groups were analyzed using Student's $t$ test (SPSS Statistics, IBM Co., Chicago, IL). A $p$ value of $\leq 0.05$ was considered statistically significant.

\section{Results}

Group comparisons demonstrated that vinblastine exposure negatively affected HERS cell proliferation (VB10 [-55\%] $p<1.0 \times 10^{-8} ;$ VB20 [-72\%] $p<1.0 \times 10^{-9}$; VB30 $[-80 \%] p<1.0 \times 10^{-10}$ ) and glutathione production (VB10 $[-36 \%] p<0.0001 ;$ VB20 [-49\%] $p<1.0 \times 10^{-6}$; VB30 [-53\%] $p<1.0 \times 10^{-7}$ ) at all doses of vinblastine. Within the no light treatment groups, $10 \mathrm{ng} / \mathrm{mL}$ vinblastine exposure resulted in a $55 \%$ decrease in cell proliferation and a $36 \%$ decrease in glutathione production compared to the control group. At 20 and $30 \mathrm{ng} / \mathrm{mL}$ vinblastine, cell proliferation and glutathione production were significantly decreased from the control and $10 \mathrm{ng} / \mathrm{mL}$ vinblastine groups $(p<0.05)$, but were not significantly different from each other. This demonstrated a distinct dose-response relationship of vinblastine on HERS cell proliferation and glutathione production, with an approximate median lethal dose $\left(\mathrm{LD}_{50}\right)$ of $10 \mathrm{ng} / \mathrm{mL}$ vinblastine.

Photobiomodulation significantly reduced vinblastine's negative effect on HERS cell proliferation $(p<0.05$; Table 1$)$ and glutathione production $(p<0.05$; Table 2$)$. When compared to the same dose of vinblastine without light treatment, the light treatment significantly increased cell proliferation at all levels of vinblastine exposure (VB10L 
Table 1. Cell Proliferation Results

\begin{tabular}{|c|c|c|c|c|c|c|}
\hline $\begin{array}{l}\text { Vinblastine } \\
\text { dose }(n g / m L)\end{array}$ & $\begin{array}{c}\text { No light } \\
\text { treatment [av. } \\
\text { cells/mL, } \times \\
10,000 \text { (SD)] }\end{array}$ & $\%$ Change & p Value* & $\begin{array}{l}\text { Light treatment } \\
\text { [av. cells/mL, } \\
10,000 \text { (SD)] }\end{array}$ & $\%$ Change & p Value \\
\hline Control/0 & $41.6(8.2)$ & - & & $50.8(14)$ & $+22 \%$ & 0.063 \\
\hline 10 & $18.6(3.4)$ & $-55 \%$ & 8.91E-09 & $27.9(5.6)$ & $+50 \%$ & 5.68E-05 \\
\hline 20 & $11.6(4.6)$ & $-72 \%$ & 2.07E-10 & $16.8(6.8)$ & $+45 \%$ & 0.041 \\
\hline 30 & $8.5(3.6)$ & $-80 \%$ & 1.19E-11 & $11.8(3.7)$ & $+39 \%$ & 0.034 \\
\hline
\end{tabular}

Average cell counts $(S D)$. $t$-test results $p$ values: ${ }^{*}$ compared to control, no light treatment; ${ }^{* *}$ compared to same dose vinblastine, no light treatment. Bold values indicate statistical significance.

[+50\%] $p<0.0001 ; \mathrm{VB} 20 \mathrm{~L}[+45 \%] p<0.05 ; \mathrm{VB} 30[+39 \%]$ $p<0.05$ ) and showed a $22 \%$ increase in control cells receiving no vinblastine, but not reaching statistical significance $(p=0.063)$. Light treatment significantly increased glutathione production at 10 and $30 \mathrm{ng} / \mathrm{mL}$ vinblastine (VB10L [+39\%] $p=0.007$; VB30 [+14\%] $p=0.025$; Table 2). Light treatment resulted in a $12 \%$ increase in glutathione production in control cells receiving no vinblastine $(\mathrm{VB}-\mathrm{L}$; $\mathrm{P}=0.13$ ), and a $19 \%$ increase at $20 \mathrm{ng} / \mathrm{mL}$ vinblastine (VB20L, $p=0.087$ ), which were not statistically significant.

At the $\mathrm{LD}_{50}$ of $10 \mathrm{ng} / \mathrm{mL}$ vinblastine, light treatment resulted in a $50 \%$ increase in cell proliferation and a $39 \%$ increase in glutathione production, thus restoring cell proliferation to $68 \%$ and glutathione production to $89 \%$ of control cells receiving no vinblastine and no light treatment.

\section{Discussion}

The results demonstrate that vinblastine has a negative effect on HERS cell proliferation and glutathione production that is in agreement with a previous study on vinblastine's effects in these types of cells. ${ }^{10}$ In addition, the results demonstrate that photobiomodulation significantly reduced these negative effects.

A consistent dose-response curve for the effects of vinblastine on in vitro cultures of murine HERS cells was established, with an approximate $\mathrm{LD}_{50}$ of $10 \mathrm{ng} / \mathrm{mL}$ vinblastine. This value is close to the estimated pharmacologic dose of vinblastine of $7.5 \mathrm{ng} / \mathrm{mL}$ given in cancer treatment, calculated from the $\mathrm{mg} / \mathrm{m}^{2}$ dose. This indicates that HERS cells are sensitive to vinblastine at/near commonly used pharmacologic doses, and adds support to clinical findings that abnormal root morphology in childhood cancer survivors is the result of damage to HERS cells proliferating at the time of chemotherapy. ${ }^{1-7}$
There was a beneficial effect of photobiomodulation on HERS cell recovery from vinblastine exposure. The greatest effects of the light treatment were noted at the $\mathrm{LD}_{50}$. Beyond this level, improvements in cell proliferation and glutathione production were likely diminished due to the extent of initial injury sustained, which surpassed the benefits derived from the light treatment. At the $\mathrm{LD}_{50}$, light treatment restored cell proliferation and glutathione production to within $68 \%$ and $89 \%$ respectively of control cells receiving no light treatment. It is unknown if this would have any beneficial outcomes on an in vivo level.

The non-statistically significant increase in glutathione production in the $20 \mathrm{ng} / \mathrm{mL}$ vinblastine group, when there were statistically significant increases in the 10 and $30 \mathrm{ng} / \mathrm{mL}$ groups, may be due to a slightly larger standard deviation measurement in this group compared to the other groups, affecting the statistics. It may also be due to naturally occurring differences in many types of mammalian cells, including epithelial cells. These differences can cause individual cells within a seemingly similar group to differ widely in their response to uniform physiological stimuli, such as oxidative stress and other environmental insults. These naturally occurring differences that cause cell-to-cell variability may develop through normal mechanisms and can include genetic differences, changes in protein expression, fluctuations in biochemical reactions, differences in cell cycle phases, and natural variation in levels of important reactants. ${ }^{15,16}$ This heterogeneous cellular response may play a role in the phenomenon of "fractional killing" of tumor cells after chemotherapy. ${ }^{16}$

It is not believed that heating the cell cultures contributed to the results obtained. Temperature probes were not utilized in this study due to previously published evidence that light therapy does not produce significant tissue heating. ${ }^{17}$ In addition, during experiments of photodynamic therapy in a

Table 2. Glutathione Assay Results

\begin{tabular}{|c|c|c|c|c|c|c|}
\hline $\begin{array}{l}\text { Vinblastine } \\
\text { dose }(n g / m L)\end{array}$ & $\begin{array}{c}\text { No light } \\
\text { treatment } \\
{[A v . R F U(\mathrm{SD})]}\end{array}$ & $\%$ Change & p Value & $\begin{array}{c}\text { Light } \\
\text { treatment } \\
{[A v . R F U(\mathrm{SD})]}\end{array}$ & $\%$ Change & p Value \\
\hline Control/ 0 & 43087 (8819) & - & & 48147 (6833) & $+12 \%$ & 0.13 \\
\hline 10 & $27600(6347)$ & $-36 \%$ & 6.14E-05 & 38389 (10910) & $+39 \%$ & 0.007 \\
\hline 20 & $21773(3873)$ & $-49 \%$ & 1.19E-07 & $25988(7160)$ & $+19 \%$ & 0.087 \\
\hline 30 & $20358(3053)$ & $-53 \%$ & 2.42E-08 & 23107 (5421) & $+14 \%$ & 0.025 \\
\hline
\end{tabular}

Average RFU (SD). $t$-test results $p$ values: *compared to control, no light treatment; ${ }^{* *}$ compared to same dose vinblastine, no light treatment. Bold values indicate statistical significance. RFU: relative fluorescence unit. 
canine model, 670-nm light at an energy density of $100 \mathrm{~J} / \mathrm{cm}^{2}$ administered directly into the brain parenchyma did not cause the temperature of brain tissue to rise by more than $1^{\circ} \mathrm{C}^{18}$

NIR light appears to exert therapeutic effects in multiple ways. Primarily, the light appears to alter the activity of cytochrome c oxidase in mitochondria ${ }^{13,14,19,20}$ improving energy metabolism and production, thus increasing energy available for cell and tissue repair. NIR light also increases the production of growth factors responsible for wound healing ${ }^{13}$ and causes the production of low level amounts of reactive oxygen species, resulting in up-regulation of genes involved in wound healing. ${ }^{21}$ In vitro studies of photobiomodulation show increased mitochondrial oxidative metabolism; ${ }^{14,19,22}$ increased cell growth in murine fibroblasts, rat osteoblasts, rat skeletal muscle cells, and human epithelial cells; ${ }^{23}$ recovery of rat neurons from toxin inactivation; ${ }^{20,22}$ accelerated wound healing; ${ }^{13,23,24}$ and protection against methanol-induced retinal toxicity. ${ }^{25}$

How photobiomodulation can assist in overcoming the cytotoxic effects of vinblastine are still unknown, but there is some evidence indicating that mitochondrial activity may be an important factor. Drug resistance by cancer cells to chemotherapeutic agents is associated with an increased expression of P-glycoprotein (Pgp) on the cell wall. ${ }^{26}$ Pgp has an integral ATP binding site and may require increased levels of ATP. Jia et al. ${ }^{27}$ demonstrated that the ATP required for this Pgp efflux pump is primarily supplied by the mitochondrial $\mathrm{F}_{1} \mathrm{~F}_{0} \mathrm{ATPase}$ pathway. Photobiomodulation has been shown to increase the amount of ATP produced in the mitochondria ${ }^{13,14,19,20}$ and also assists in upregulating genes necessary for cellular healing. ${ }^{20}$ Although there is no published literature to suggest it, if photobiomodulation is able to induce the cells to produce more Pgp, this, along with increased ATP production, might be able to prevent apoptosis of vinblastine-treated HERS cells in a manner similar to Pgp-associated vinblastine-resistance in tumor cells. More research is required to test this theory.

\section{Conclusion and Summary}

This study is a first step in determining the possible benefits of photobiomodulation to HERS cells in this population of cancer patients. This preliminary work demonstrated a beneficial effect of photobiomodulation on in vitro cultures of murine HERS cells injured by the chemotherapeutic agent vinblastine. Much further research is needed to address the in vivo effects, but photobiomodulation is the first treatment to demonstrate a beneficial effect on HERS cells after vinblastine exposure.

\section{Acknowledgments}

This work was supported by the National Aeronautics and Space Administration Grant \# NNM05AB48C; the Bleser Foundation Endowed Professorship and Chad Baumann Neurology Research Endowment at the Medical College of Wisconsin; and the Marquette University School of Dentistry Pediatric Faculty Fund.

\section{Author Disclosure Statement}

No competing financial interests exist.

\section{References}

1. Goho, C. (1993). Chemoradiation therapy: effect on dental development. Pediatr. Dent. 15, 6-12.

2. Kaste, S.C., Hopkins, K.P., Jones, D., Greenwald, C.A., and Santana, V.M. (1997). Dental abnormalities in children treated for acute lymphoblastic leukemia. Leukemia 11, 792-796.

3. Vaughan, M.D., Rowland, C.C., Tong, X., et al. (2005). Dental abnormalities after pediatric bone marrow transplantation. Bone Marrow Transplant. 36, 725-729.

4. Rosenberg, S.W., Kolodney, H., Wong, G., and Murphy, M.L. (1987). Altered dental root development in long-term survivors of pediatric acute lymphoblastic leukemia. Cancer 59, 1640-1648.

5. Sonis, A.L., Tarbell, N., Valachovic, R.W., Gelber, R., Schwenn, M., and Sallan, S. (1990). Dentofacial development in long-term survivors of acute lymphoblastic leukemia: a comparison of three treatment modalities. Cancer 66, 26452652.

6. Nasman, M., Bjork, O., Soderhall, S., Ringden, O., and Dahllof, G. (1994). Disturbances in the oral cavity in pediatric long-term survivors after different forms of anti-neoplastic therapy. Pediatr. Dent. 16, 217-223.

7. Duggal, M.S. (2003). Root surface areas in long-term survivors of childhood cancer. Oral Oncol. 39, 178-183.

8. Zeichner-David, M., Oishi, K., Su, A., et al. (2003). Role of Hertwig's epithelial root sheath cells in tooth root development. Dev. Dyn. 8, 651-663.

9. Yamamoto, H., Cho, S.W., Kim, E.J., Kim, J.Y., Fujiwara, N., and Jung, H.S. (2004). Developmental properties of the Hertwig's epithelial root sheath in mice. J. Dent. Res. 83, 688-692.

10. Heritier, M., Robert, J.L., and Baillez, Y. (1987). Cellular behavior in epithelial root sheath following vinblastine administration in mouse. J. Biol. Buccale 15, 11-22.

11. Beck, W.T. (1980). Increase by vinblastine of oxidized glutathione in cultured mammalian cells. Biochem. Pharmacol. 299, 2333-2337.

12. Pompella, A., Visvikis, A., Paolicchi, A., De Tata, V., and Casini, A.F. (2003). The changing faces of glutathione, a cellular protagonist. Biochem. Pharmacol. 66, 1499-1503.

13. Babapour, R., Glassberg, E., and Lask, G. (1995). Low-energy laser systems. Clin. Dermatol. 13, 87-90.

14. Desmet, K.D., Paz, D.A., Corry, J.J., et al. (2006). Clinical and experimental applications of NIR-LED photobiomodulation. Photomed. Laser Surg. 24, 121-128.

15. Burke, J.M., and Hjelmeland, L.M. (2005). Mosaicism of the retinal pigment epithelium: seeing the small picture. [Review] Mol. Interv. 5, 241-249.

16. Spencer, S.L., Gaudet, S., Albeck, J.G., Burke, J.M., and Sorger, P.K. (2009). Non-genetic origins of cell-to-cell variability in TRAIL-induced apoptosis. Nature 459, 428-433.

17. Karu, T.I. (1989). Photobiology of low-power laser effects. Health Phys. 56, 691-704.

18. Schmidt, M.H., Meyer, G.A., Reichert, et al. (2004). Evaluation of photodynamic therapy near functional brain tissue in patients with recurrent brain tumors. J. Neurooncol. 67, 201-207.

19. Yu, W., Main, J., McGowan, M., Ippolito, K., and Lanzafame, R. (1997). Photomodulation of oxidative metabolism and electron chain enzymes in rat liver mitochondria. Photochem. Photobiol. 66, 866-871.

20. Wong-Riley, M.T., Liang, H.L., Eells, J.T., et al. (2005). Photobiomodulation directly benefits primary neurons functionally inactivated by toxins. J. Biol. Chem. 280, 4761-4771. Epub 2004 Nov. 
21. Arnold, R.S., Shi, J., Murad, E., et al. (2001). Hydrogen peroxide mediates the cell growth and transformation caused by mitogenic oxidase Nox1. Proc. Natl. Acad. Sci. USA 98, 5550-5555.

22. Wong-Riley, M.T., Bai, X., Buchmann, E., and Whelan, H.T. (2001). Light-emitting diode treatment reverses the effect of TXX on cytochrome oxidase in neurons. Neuroreport 12, 3033-3037.

23. Whelan, H.T., Smits, R.L., Buchmann, E.V., et al. (2001). Effect of NASA light-emitting diode irradiation on wound healing. J. Clin. Laser Med. Surg. 19, 305-314.

24. Whelan, H.T., Buchmann, E.V., Dhokalia, A., et al. (2003). Effect of NASA light-emitting diode irradiation on molecular changes for wound healing in diabetic mice. J. Clin. Laser Med. Surg. 21, 67-74.

25. Eells, J.T., Henry, M.M., Wong-Riley, M.T., et al. (2003). Therapeutic photobiomodulation for methanol-induced retinal toxicity. Proc. Natl. Acad. Sci. USA 100, 3439-3444.
26. Endecott, J.A., and Ling, V. (1989). The biochemistry of Pglycoprotein-mediated multidrug resistance. Annu. Rev. Biochem. 58, 137-171.

27. Jia, P.D., Allen, M.G., Macey, M.F., Grahn, A.C.N., and Kelsey, S.M. (1997). Mitochondrial electron transport chain activity, but not ATP synthesis, is required for drug-induced apoptosis in human leukaemic cells: a possible novel mechanism of regulating drug resistance. Brit. J. Haematol. 98, 686-698.

Address correspondence to: Brian Hodgson, D.D.S. Marquette University School of Dentistry 1801 W. Wisconsin Ave., Rm 326 Milwaukee, WI 53233 414-288-1566

E-mail: brian.hodgson@marquette.edu 
